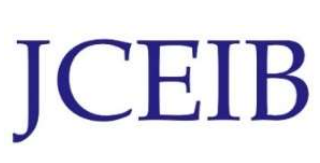

Journal Chemical Engineering and Industrial Biotechnology (JCEIB) Open Access

Volume 4 pp. 44-52; March 2018

(C) Universiti Malaysia Pahang Publisher

DOI: https://doi.org/10.15282/JCEIB-V4-05.30/9/2018/4.4

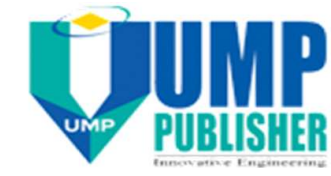

\title{
DESTABILIZATION OF CRUDE OIL EMULSION VIA ELECTROCOAGULATION METHOD
}

\author{
Firdos. M. Abdulla, Nour Hamid Abdurahman* \\ Chemical Engineering Department University of Technology-Baghdad-Iraq \\ * Corresponding author: E-mail: nour2000_99@yahoo.com \\ Tel.: +60129134403
}

\begin{abstract}
Formation of emulsions during oil production and processing is a costly problem, both in terms of chemicals used and production losses. Conventional ways of breaking crude oil emulsion are disadvantageous from both economic and environmental perspectives. In this paper, the potentials of electrocoagulation technology in destabilization of crude oil emulsion were investigated. The crude oil was obtained from Petronas Refinery Melaka, Malaysia. For stability performance test, Span 80 was used as emulsifier, while for chemical destabilization performance test, Hexylamine was used. The electrocoagulation method was used for destabilization of W/O emulsion. For electrocoagulation destabilization, three factors namely; voltages $15-50 \mathrm{~V}$, current density $1.04-3.94 \mathrm{mAcm}^{-}$ ${ }^{2}$, and $\mathrm{NaCl}$ concentration $0.5-2.5 \mathrm{~g} / \mathrm{L}$. The electrocoagulation destabilization showed that the best water separation efficiency was achieved at voltage $50 \mathrm{~V}$, current density 3.94 $\mathrm{mAcm}^{-2}$, and $\mathrm{NaCl}$ concentration $2.5 \mathrm{~g} / \mathrm{L}$, whereas the separation efficiency reached at $98 \%$. In addition, electrocoagulation of $\mathrm{W} / \mathrm{O}$ emulsion separation is advantageous as it was simple to be operated, low cost and more identical, and then successfully applied on destabilization of $\mathrm{W} / \mathrm{O}$ crude oil emulsions on the industry.

Keywords: crude oil; destabilization; electrocoagulation, chemical, W/O emulsion
\end{abstract}

\subsection{INTRODUCTION}

Crude oil production from the fields there is a production of water with oil this is called an emulsion which either be controlled or avoided. This emulsion resulted in an increase in viscosity which can very affect the production of oil from sand phase up to flow line. Failure to separate the oil and water mixture efficiently and effectively could result in problems such as overloading of surface separation equipment, increased cost of pumping wet crude, and corrosion problems (Salam, Alade, Arinkoola, and Opawale, 2013).The two most common emulsion types are water droplet dispersed in the oil phase and termed as water-in-oil emulsion $\mathrm{W} / \mathrm{O}$ and if the oil is the dispersed phase, it is termed oil-in-water $\mathrm{O} / \mathrm{W}$ emulsion (Langevin, Poteau, Hénaut, and Argillier, 2004).Generally ,the presence of emulsifying agents which are naturally Destabilization, the separation of an emulsion into its component phases, is a two-step process. The first step is flocculation (aggregation, agglomeration, or coagulation). The second step is coalescence. Either of these steps can be the rate-determining step in emulsion breaking (Kalogirou, 2014). The undesired emulsion is essential to be demulsified to have good quality of the crude oil. Although great effort has been made to demulsified these emulsions, it remains a challenge to effectively break up undesired emulsions by understand the mechanism of formation and stabilization of the emulsion. The stabilization and formation of emulsion 
are crucial parts to study before demulsified the stable emulsion, results in higher separation of water presented in the crude oil (Nor Ilia Anisa, 2011).

In various sectors of industry, including petroleum refinery, natural gas processing and transmission, as well as oil and gas production, oil-water emulsion is generated. These emulsions cause a number of operational problems such as tripping of separation equipment in gas-oil separating plants, production of off-spec crude oil, and creating high pressure drops in flow lines. Emulsions have to be treated to remove the dispersed water and associated inorganic salts in order to meet crude specification for transportation, storage and export and to reduce corrosion and catalyst poisoning in downstream processing facilities. The conventional ways in destabilization crude oil emulsions has disadvantages from both environmental and economic perspectives (S. Kokal et al., 2002).Emulsions of crude oil and water can be encountered at many stages during drilling, producing, transporting and processing of crude oils and in many locations such as in hydrocarbon reservoirs, well bores, surface facilities, transportation system and refineries. Also, emulsions usually exhibit viscosities significantly higher than crude oil, thus increasing the energy input required for transport in pipeline (Peña, Hirasaki, and Miller, 2005).

\subsection{MATERIALS AND METHODS}

\subsection{Materials}

In this study, the type of crude oil was obtained from Petronas Refinery at Malaka was used. The crude oil type was light crude oil, which was with a volume ratio of (50-50) vol. \%. For further investigation; several types of chemicals were used in order to carry out the emulsion's stability investigation and their specific characterization. For emulsion's stabilization the type of emulsifier Span 80 was used. The other surfactant used as demulsifying agent in order to break the W/O emulsions, this demulsifier is Hexylamine. The chemicals used in this research supplied from Sigma Company.

\subsubsection{Electrocoagulation}

The destabilization process of W/O emulsions was conducted by using electrocoagulation system. The electrocoagulation experiment is a monopolar batch reactor with two electrodes (all made of the same material aluminum because it is cheap and easy to produce) connected in parallel to a digital DC power supply $(110 \mathrm{~V}, 10 \mathrm{~A})$. The electrodes were disposed vertically in the cell at a distance from each to other. The volume of the treated emulsion was $500 \mathrm{ml}$. The runs were performed at room temperature $\left(25-28{ }^{\circ} \mathrm{C}\right)$. The electrocoagulation system used in this study is shown in Figure 1.

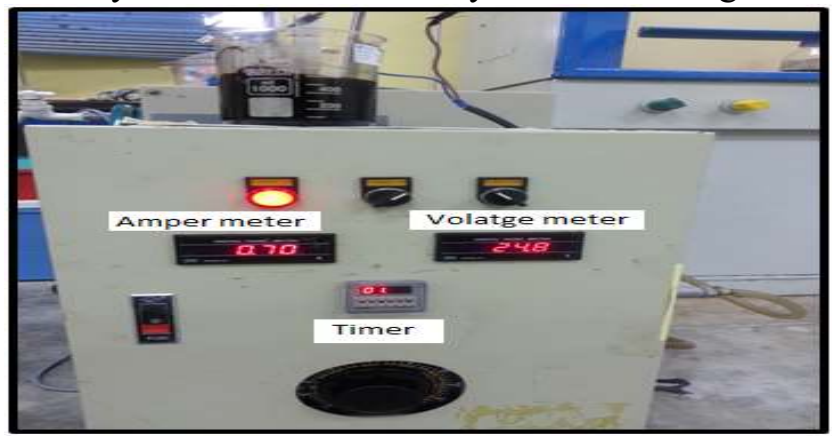

Figure 1. Electrocoagulation system 


\subsubsection{Emulsion Preparation}

In the laboratory, the ratio of water-in-oil emulsion (50-50) vol. \% was prepared. Emulsions were in $500 \mathrm{ml}$ graduated beakers, with ranges by volume of water and oil phase. The prepared emulsion was checked whether (W/O or $\mathrm{O} / \mathrm{W}$ ) using test tube method and only $\mathrm{W} / \mathrm{O}$ emulsion was selected for further steps. For emulsion preparation the stabilizing agent (surfactant) was used Span 80 with concentration 0.5 vol. \%. To prepare $\mathrm{W} / \mathrm{O}$ emulsions the emulsifier was dissolved into the continuous phase (crude oil) and vigorously sheared for 3 minutes. Then the dispersed phase (water) was added slowly to the oil phase while mixing in a standerd three blade propeller and sheared for 4 minutes with mixing speed of $1000 \mathrm{rpm}$ speed at temperature $28-30^{\circ} \mathrm{C}$. Figure 2 show the steps for preparing $(\mathrm{W} / \mathrm{O})$ emulsion.

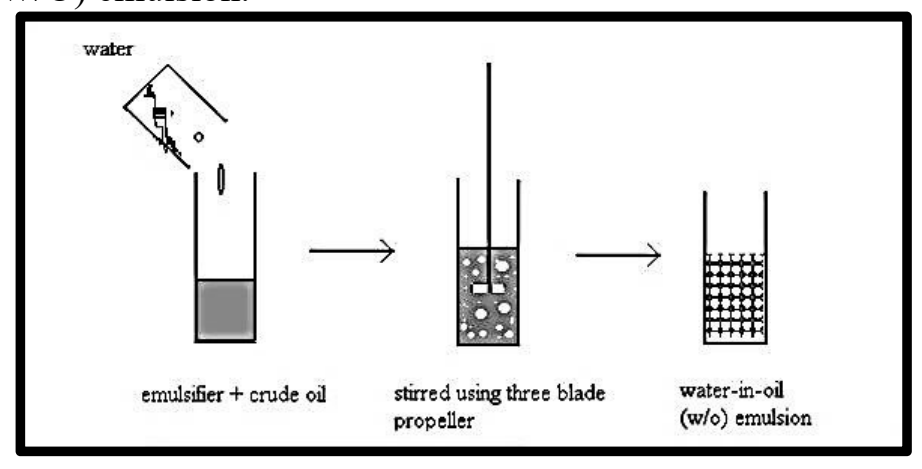

Figure 2: Preparing (W/O) emulsion system

\subsection{RESULTS AND DISCUSSION}

The characteristics of the crude oil were carried out through the physical method. For the physical characterizations of crude oil such as density, viscosity, API gravity, surface tension and interfacial tension were determined.

\subsection{Physical Characterization}

The physical properties where determined to understand the behavior of the crude oil with regards to the emulsion stability and formation (Nadkarni, 2007). In this study it was obtained that the crude oil behaves as the light crude oil as it has an API degree is 34 . Where, it is relevant to the density of the crude oil as it was about $0.8528 \mathrm{~g} / \mathrm{cm}^{3}$. The crude oil viscosity is also one of the important parameters which deal with the rheological studies, the viscous oils can create many problems throughout the system, and may cause difficulties during pumping and transportation as well (Rand, 2003). It was found that the crude oil viscosity is $91.25 \mathrm{mPa} . \mathrm{s}$ at $25{ }^{\circ} \mathrm{C}$. The result of viscosity indicated that the amount of heavy fraction is more than the light fraction in the crude oil.

The pour point is one of the flowing properties of the crude oil. The study of pour point is very important, especially during the transportation, whatever, the pour point is the lowest temperature at which the oil cans no longer stops the following and became semisolid. Pour point of the crude oil increases by increasing the specific gravity. The pour point of crude oils varies from $-60^{\circ} \mathrm{C}$ to $+30^{\circ} \mathrm{C}$. During preheating from $45-65^{\circ} \mathrm{C}$ the temperature of the pour point decreases and this is due to the paraffinic crystal existed in crude oil (Taraneh, Rahmatollah, Hassan, and Alireza, 2008). In this research the crude oil has the pour point $-11^{\circ} \mathrm{C}$. The measurements of surface tension and interfacial tension 
were also conducted for the crude oil. The physical properties of the crude oil are shown in Table 1.

Table 1. Physical properties of crude oil

\begin{tabular}{ll}
\hline Properties & Measurement \\
\hline Viscosity $(\mathrm{cp})$ at $28{ }^{\circ} \mathrm{C}$ & 91.25 \\
Density $\left(\mathrm{g} / \mathrm{cm}^{3}\right)$ & 0.8528 \\
API Gravity & 34 \\
Pour point $(\mathrm{C})$ & -11 \\
Surface Tension $(\mathrm{mN} / \mathrm{m})$ at $25{ }^{\circ} \mathrm{C}$ & 62.983 \\
Interfacial Tension $(\mathrm{mN} / \mathrm{m})$ at $25^{\circ} \mathrm{C}$ & 5.00 \\
Shear Rate $\left(\mathrm{sec}{ }^{-1}\right)$ & 51 \\
Shear Stress $(\mathrm{pa})$ & 4.765 \\
\hline
\end{tabular}

\subsection{Characterization of the Emulsion}

The rheological study of the emulsion has a great importance in understanding the formation and stability mechanism of an emulsion. Therefore, the effect of two important parameters such as viscosity and emulsion droplet size were investigate as shown in Table 2.

Table 2: Physicochemical properties of (W/O) crude oil emulsion

\begin{tabular}{ll}
\hline Properties & Measurement \\
\hline $\begin{array}{l}\text { droplets size of }(\mathrm{W} / \mathrm{O}) \text { emulsion } \mu \mathrm{m} \\
1 \% \text { of span80 }(50-50 \%) \text { phase ratio } \\
\text { droplets size of }(\mathrm{W} / \mathrm{O}) \text { emulsion } \mu \mathrm{m}\end{array}$ & 83.123 \\
$\begin{array}{l}2 \% \text { of span } 80(50-50 \%) \text { phase ratio } \\
\text { viscosity }(\mathrm{cp}) \text { at } 28^{\circ} \mathrm{C}\end{array}$ & 80.754 \\
& 402.8 \\
shear rate $(1 / \mathrm{sec})$ & 23.8 \\
shear stress (pa) & 9.61
\end{tabular}

\subsection{Viscosity of the Emulsion}

The actual viscosity of the emulsion was investigating under the effect of shear stress, shear rate, stirring intensity (during the emulsion preparation). Viscosity of an emulsion is proportional to the viscosity of continuous phase (crude oil) and is defined as the relationship between shear stress and shear rate. Highly viscous oils regularly form more stable emulsions these oils cause emulsions difficult to treat, because they decrease the movement of droplets, delaying the coalescence (S. L. Kokal, 2005).

\subsubsection{Effect of Shear Rate on the Viscosity of the Emulsion}

Usually, viscosity is a function of shear rate. Figure 3; illustrate the effects of shear rate on the viscosity of $\mathrm{W} / \mathrm{O}$ emulsions at phase ratio (50-50) \%, prepared with emulsifier Span 80 at 0.5 vol. \% concentration. As well as different stirring intensity $(50,100,150$ and 200) rmp were applied for the viscosity measurement. 
It is clear that in all types of the samples, the apparent viscosity showed a reduction was recorded from (81.8 to $43.2 \mathrm{cp}$ ) with increasing the shear rate from (17 to 68) $\mathrm{Sec}^{-1}$. This may be attributed to the breakup of flocculated particles caused by the force carried by the shear rate and hence reduced the viscosity. However, the emulsion prepared with Span 80 exhibited higher viscosity the reason is may be the more stability of the emulsions as analyzed through the microscopic images.(Fingas \& Fieldhouse, 2014) stated that stable emulsions are more viscos comparing to the loss emulsions, i.e. means that the flow encounters less resistance at higher shear rates. This is due to the molecular chains found in the crude oil. As the shear rate increases, the chain type molecules disentangled, stretched, and reoriented parallel to the driving force, and hence reduced the crude oil viscosity (Ghannam \& Esmail, 2006).

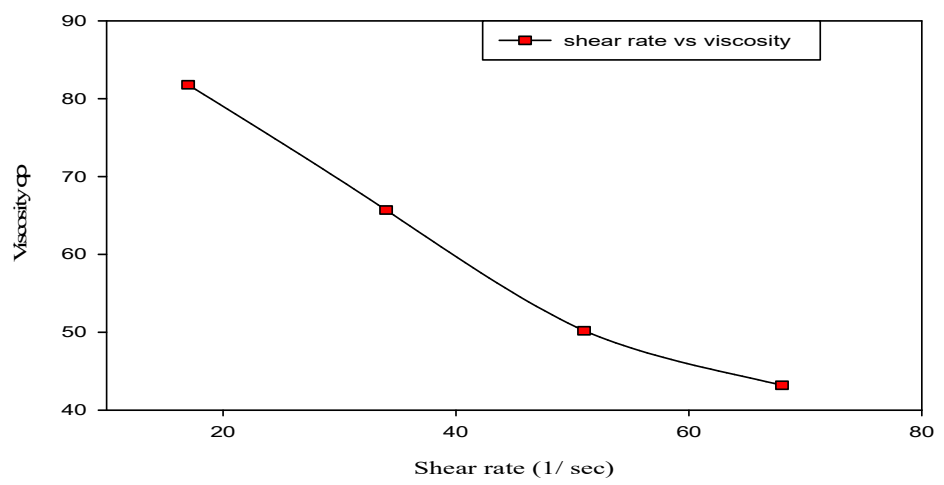

Figure 3: Effect of shear rate on viscosity of $50-50 \% \mathrm{~W} / \mathrm{O}$ emulsion with Span 80 prepared at $1000 \mathrm{rpm}$

\subsubsection{Effect of Shear Rate on the Shear Stress}

The effects of shear rate and shear stress on the viscosity of crude oil emulsions are the important factors to understand the flow behavior of the emulsions. Therefore, the measurement of viscosity and shear stress of all emulsions were investigated versus shear rate. Through these measurements, the details of Newtonian or Non-Newtonian flow behavior of the emulsion can be obtained. Figure 4, indicate the complete information about the flow behavior of prepared W/O emulsion formed with Span 80 different shear rates $(17,34,51$ and 68$) 1 / \mathrm{sec}$ and applied stirring intensity $(50,100,150$ and 200). It can be observed that the viscosity and shear stress of the emulsion are dependent on the shear rate. The shear stress of the emulsion increased gradually and significantly with the shear rate which indicates crude oil exhibiting Non-Newtonian behaviors this is due to the relationship between the shear rate and the applied stress is linear (Ghannam \& Esmail, 2005). 


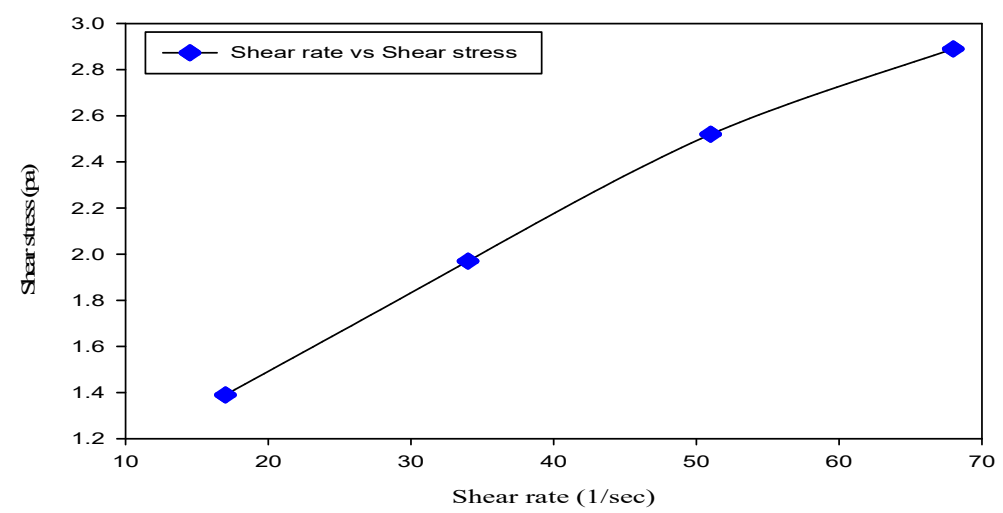

Figure 4. Effect of shear rate and shear stress on the viscosity of $50-50 \% \mathrm{~W} / \mathrm{O}$ emulsion stabilized with Span 80 prepared at $1000 \mathrm{rpm}$.

\subsection{Droplet Size of the Emulsions}

The droplet size of the emulsions is very important factor in studies of the emulsions. The droplet size has significant impact on the stability and viscosity of the emulsion. Importantly, there are some factors that can influence the property of the droplet size, for example; emulsifier type, emulsifier concentration, volume fraction water (dispersed phase), and stirring speed. The emulsifier type and emulsifier concentration are very effective on the droplet size of the emulsions (Windhab, Dressler, Feigl, Fischer, and Megias-Alguacil, 2005), the emulsifier concentration $1 \%$ and $2 \%$. When increased the emulsifier concentration the droplets size decreased (83.123 and 80.754) $\mu \mathrm{m}$, that one, if the concentration of emulsifier is sufficiently high, then the coalescence of water droplets is stopped this is leading to stable emulsions.(Wang, Gong, and Angeli, 2011). Figure 6and 7 display the microscopy images of the droplet sizes.

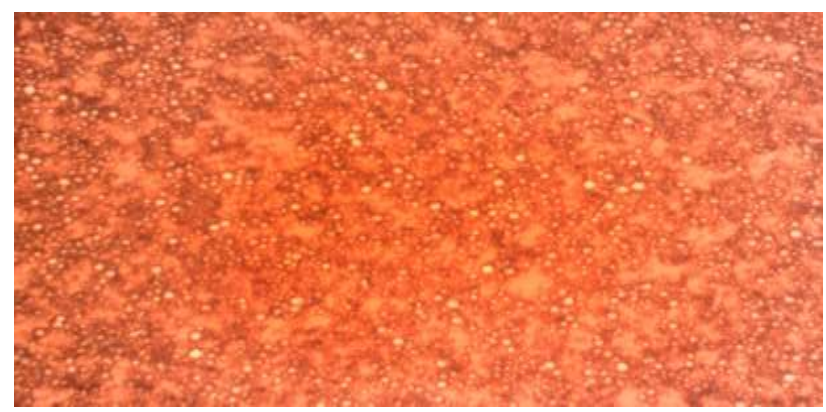

Figure 5: Optical microscopy images of 50-50\% W/O emulsions stabilized with 1 vol. $\%$ emulsifier prepared at $1000 \mathrm{rpm}$. 


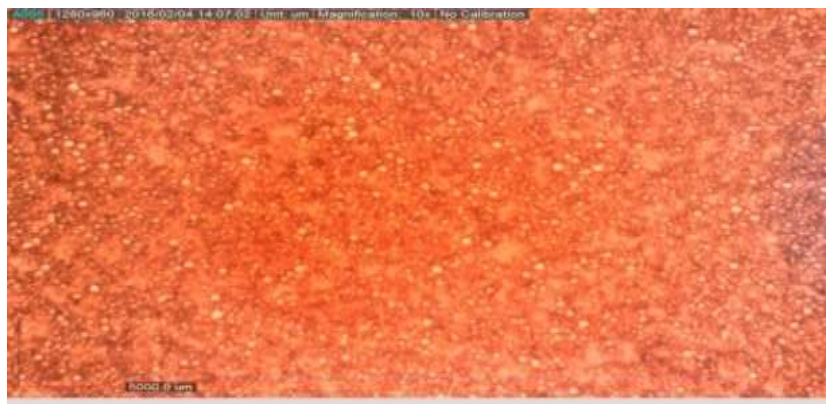

Figure 6: Optical microscopy images of 50-50\% W/O emulsions stabilized with 2 vol. $\%$ emulsifier prepared at $1000 \mathrm{rpm}$.

\subsection{Electrocoagulation Destabilization}

For electrocoagulation operating conditions, the main effects of many factors; voltages 15-50 V, current density 1.04-3.94 $\mathrm{mAcm}^{-2}$, and $\mathrm{NaCl}$ concentration $0.5-2.5 \mathrm{~g} / \mathrm{L}$ on water separation efficiency.

\subsubsection{Effects of Current Density}

The current density is defined as the electric current per unit area an important operating factor manipulating the performance of electrochemical process which describes the coagulant dosage (Ün et al., 2006). To identify the current density effect, four voltages were applied. Figure 7 describes the effect of current density on the water separation efficiencies; it can be seen from the figure that the rate of water separation efficiency increases with applied current density. The water separation efficiency was $98 \%$ at $3.94 \mathrm{~mA} \mathrm{~cm}^{-2}, 92 \%$ at $2.84 \mathrm{~mA} \mathrm{~cm} \mathrm{~cm}^{-2}, 88 \%$ at $1.95 \mathrm{~mA} \cdot \mathrm{cm}^{-2}$ and $80 \%$ at $1.04 \mathrm{~mA} \cdot \mathrm{cm}^{-2}$ after 23 -minute reaction. At a high current density, increasing the generation of hydrogen gas formed at electrode surfaces. This leads to an increase in the number of gas bubbles inside the beaker. Subsequently, the attachment step between gas bubbles and oil drops is higher, and more oil drops are carried out by gas bubbles i.e. the initial high rate of oil separation may be recognized to the high frequency of collision between the neutralized oil drops (Un et al., 2009).

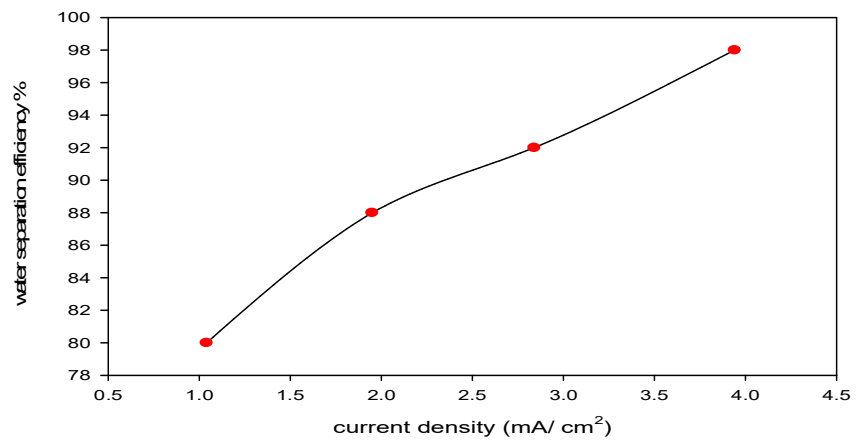

Figure 7: Variation of water separation efficiency with current densities

\subsubsection{Effects of $\mathrm{NaCl}$ Concentration}

The effect of sodium chloride concentration on the percentage of separation was illustrated in Figure 8. Increasing the sodium chloride concentration was effective on the separation efficiency. The results indicate that the percentage of water separation increased by increasing the amount of sodium chloride. When the concentration of $\mathrm{NaCl}$ 
in solution increases, solution conductivity was raised and decreases the size of hydrogen gas bubbles. Since the buoyancy of smaller bubbles is lower than larger bubbles, they rise slowly to the surface with high chances for collision with oil drops. This leads to an improvement in the percentage of separation.(Daneshvar et al., 2003). Clearly, electrocoagulation process with $2 \mathrm{~g} / \mathrm{L} \mathrm{NaCl}$ and $2.5 \mathrm{~g} / \mathrm{L} \mathrm{NaCl}$, the separation efficiency was reached at $88 \%$ and $92 \%$ respectively.

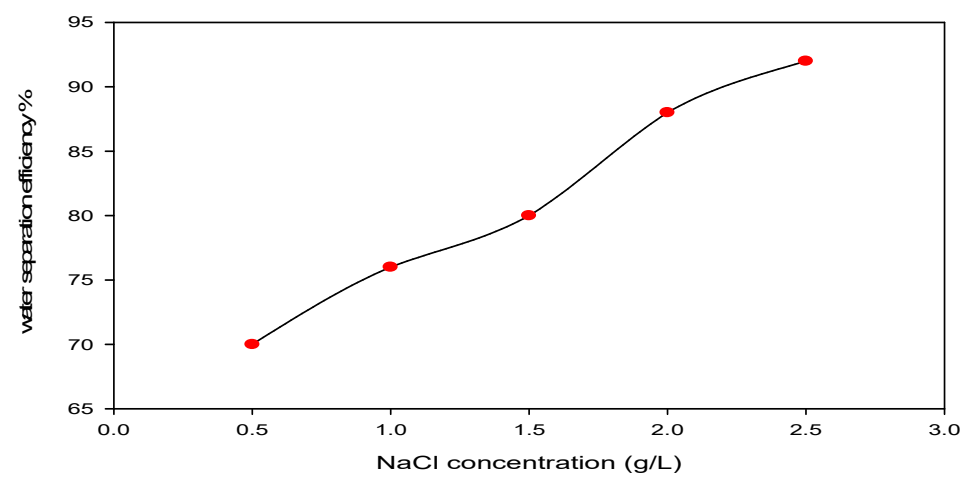

Figure 8: Variation of water separation efficiency with $\mathrm{NaCl}$ concentration

\subsection{CONCLUSIONS}

In this paper an investigation on stabilization and destabilization of water-in-crude oil emulsion was investigated. The stabilization of $\mathrm{W} / \mathrm{O}$ emulsion is a serious challenge, which can bear some serious problems in separators and refining processes. It was found that the density, viscosity, pour point, and API gravity of crude oil were $0.8528 \mathrm{~g} / \mathrm{cm}^{3}$, $91.25 \mathrm{cp},-11{ }^{\circ} \mathrm{C}$, and 34 at room temperature, respectively. After crude oil characterization, the emulsion of W/O were prepared using emulsifier Span 80 with concentration of $0.5 \%(\mathrm{v} / \mathrm{v})$ at w/o ratio of $50: 50 \%(\mathrm{v} / \mathrm{v})$. It was found that the $\mathrm{W} / \mathrm{O}$ emulsions were more viscous and dense than the crude oil. The destabilization process was accomplished using electrocoagulation destabilization method, in this step used stabilizer (Span 80) for the stabilization part was chosen to pursue with the destabilization of $\mathrm{W} / \mathrm{O}$ emulsion. The chemical destabilization process was performed using Hexylamine as a destabilizer to get the best water separation efficiency. At the highest current density, the fastest treatment rate for $\mathrm{W} / \mathrm{O}$ emulsion was obtained. Increasing concentration of $\mathrm{NaCl}$ as coagulant aid, increased water separation efficiency $92 \%, 88 \%, 80 \%, 76 \%$ and $70 \%$ with $2.5,2,1.5,1,0.5 \mathrm{~g} / \mathrm{L}$ respectively, therefore decreased energy consumption in the electrocoagulation system. The optimal operational factors can be estimated as a function of energy consumption, and economic situation where the electrocoagulation is applied.

\section{REFERENCES}

Fingas, M., and Fieldhouse, B. (2014). Water-in-oil emulsions: formation and prediction. Handbook of Oil Spill Science and Technology, 225.

Ghannam, M. T., and Esmail, N. (2005). Yield stress behavior for crude oil-polymer emulsions. Journal of Petroleum Science and Engineering, 47(3), 105-115.

Ghannam, M. T., and Esmail, N. (2006). Flow enhancement of medium-viscosity crude oil. Petroleum Science and Technology, 24(8), 985-999. 
Kalogirou, A. (2014). Nonlinear dynamics of surfactant-laden multilayer shear flows and related systems. Imperial College London.

Kokal, S., Dawood, N., Fontanilla, J., Al-Ghamdi, A., Nasr-El-Din, H., and Al-Rufaie, Y. (2002). Productivity decline in oil wells related to asphaltene precipitation and emulsion blocks. In SPE Annual Technical Conference and Exhibition. Society of Petroleum Engineers.

Kokal, S. L. (2005). Crude oil emulsions: A state-of-the-art review. SPE Production and Facilities, 20(01), 5-13.

Langevin, D., Poteau, S., Hénaut, I., and Argillier, J. F. (2004). Crude oil emulsion properties and their application to heavy oil transportation. Oil and Gas Science and Technology, 59(5), 511-521.

Nadkarni, R. A. (2007). Guide to ASTM test methods for the analysis of petroleum products and lubricants. ASTM International West Conshohocken.

Nor Ilia Anisa, A. (2011). Demulsification of water-in-oil (W/O) emulsion by microwave heating technology. Universiti Malaysia Pahang.

Peña, A. A., Hirasaki, G. J., and Miller, C. A. (2005). Chemically induced destabilization of water-in-crude oil emulsions. Industrial and Engineering Chemistry Research, 44(5), 1139-1149.

Rand, S. J. (2003). Significance of tests for petroleum products (Vol. 1). ASTM International.

Salam, K. K., Alade, A. O., Arinkoola, A. O., and Opawale, A. (2013). Improving the demulsification process of heavy crude oil emulsion through blending with diluent. Journal of Petroleum Engineering, 2013.

Taraneh, J. B., Rahmatollah, G., Hassan, A., and Alireza, D. (2008). Effect of wax inhibitors on pour point and rheological properties of Iranian waxy crude oil. Fuel Processing Technology, 89(10), 973-977.

Wang, W., Gong, J., and Angeli, P. (2011). Investigation on heavy crude-water two phase flow and related flow characteristics. International Journal of Multiphase Flow, 37(9), 1156-1164.

Windhab, E. J., Dressler, M., Feigl, K., Fischer, P., and Megias-Alguacil, D. (2005). Emulsion processing-from single-drop deformation to design of complex processes and products. Chemical Engineering Science, 60(8), 2101-2113. 